\title{
A New Mechanism of Dynamic Phase Transformations in An Isothermal Forged Beta-Gamma Intermetallic Alloy
}

\author{
Zhengang Zhang ${ }^{1}$, Shoujiang $Q u^{1, *}$, Guorong Cui ${ }^{2, *}$, Aihan Feng ${ }^{1}{ }^{\circledR}$, Jun Shen ${ }^{1,3}$ \\ and Daolun Chen $4, *$ (D) \\ School of Materials Science and Engineering, Tongji University, Shanghai 201804, China \\ 2 School of Materials Science and Engineering, Harbin Institute of Technology, Weihai 264209, China \\ College of Mechatronics and Control Engineering, Shenzhen University, Shenzhen 518060, China \\ 4 Department of Mechanical and Industrial Engineering, Ryerson University, Toronto, ON M5B 2K3, Canada \\ * Correspondence: qushoujiang@tongji.edu.cn (S.Q.); cuiguorong@hitwh.edu.cn (G.C.); \\ dchen@ryerson.ca (D.C.); Tel.: +416-979-5000-6487 (D.C.)
}

Received: 27 July 2019; Accepted: 27 August 2019; Published: 30 August 2019

check for updates

\begin{abstract}
A new mechanism of dynamic phase transformations of $\alpha_{2} \leftrightarrow \gamma$ in an isothermally forged $\gamma$-TiAl-based alloy that occur simultaneously during a short-term exposure at $1000{ }^{\circ} \mathrm{C}$ is identified in this study. In the heating process, $\gamma$ phase significantly decreases through a phase transformation of $\gamma \rightarrow \alpha_{2}$, while new $\gamma$ lamellae are precipitated in the interior of equiaxed grains of $\alpha_{2}$ phase through a phase transformation of $\alpha_{2} \rightarrow \gamma$. The reasons for the presence of these two inverse phase transformations $\alpha_{2} \leftrightarrow \gamma$ occurring simultaneously are discussed.
\end{abstract}

Keywords: titanium aluminide; phase transformation; precipitation; microstructure

\section{Introduction}

Intermetallic $\gamma$-TiAl-based lightweight alloys are well-suited for the aerospace applications since they combine a low density with high strength and superior oxidation resistance at elevated temperature [1-3]. $\beta$-solidifying TiAl-based alloys usually have a better superplastic ability than traditional two-phase $\left(\gamma+\alpha_{2}\right)$ TiAl alloys, as the $\beta / \beta_{0}$ phase (also called as B2 phase) can provide more slip systems at high temperature [4]. The temperature for the typical applications of TiAl-based alloys ranges from $600{ }^{\circ} \mathrm{C}$ to $900{ }^{\circ} \mathrm{C}$ [5], while the minimum temperature of phase transformation (labeled as $\mathrm{T}_{\min }$ ) is $\sim 1160{ }^{\circ} \mathrm{C}$ [6]. Huang et al. [7] reported that $\alpha_{2}$ lamellae in the as-HIP TiAl alloys decomposed through phase transformations of $\alpha_{2} \rightarrow \gamma, \alpha_{2} \rightarrow$ B2 (or B2 $+\omega$ ) and $\alpha_{2}+\gamma \rightarrow$ B2 (or B2 $+\omega$ ) when exposed at $700{ }^{\circ} \mathrm{C}$ for $10,000 \mathrm{~h}$. Therefore, TiAl-based alloys without thermal deformation are metastable thermodynamically after annealing for a long time at a temperature below $\mathrm{T}_{\min }$. In the process of forging or rolling at high temperature, stress-induced phase transformation [8], temperature-induced phase transformation, dynamic recovery and dynamic recrystallization occur simultaneously $[9,10]$. The fraction of $\gamma, \alpha_{2}$ and B2 phases varies with forging temperature and deformation amount of ingot [11]. To prevent grain growth, the wrought cakes are usually air-cooled to room temperature after forging, which do not have sufficient time to reach the phase equilibrium at low temperature. How the microstructure of these forgings changes during heating below $\mathrm{T}_{\min }$ needs to be understood. This study is aimed at understanding the phase transformation mechanisms of isothermally forged beta-gamma TiAl-based alloy heated to $1000{ }^{\circ} \mathrm{C}$ and attempting to infer the stress-induced phase transformations in the forging process. 


\section{Materials and Methods}

In the present study, the beta-gamma TiAl-based alloy with a nominal composition of Ti-44Al-4Nb-1.5Cr-0.1Mo-0.1B (at.\%) was prepared by double vacuum consumable arc melting and then hot isostatically pressed (HIP) at $1300^{\circ} \mathrm{C}$ under $180 \mathrm{MPa}$ for $2 \mathrm{~h}$ followed by furnace cooling (FC). As shown in Figure 1, the cylindrical sample $(\Phi 209 \mathrm{~mm} \times 330 \mathrm{~mm})$ was preheated at $1200{ }^{\circ} \mathrm{C}$ for $6 \mathrm{~h}$, and then immediately isothermal forged (ISF) at $1070{ }^{\circ} \mathrm{C}$ twice with a rotation of $180^{\circ}$ before the second compression, with a total strain of $60 \%$ at a rate of $0.005 \mathrm{~s}^{-1}$, followed by air cooling (AC). Another $75 \%$ strain with the same process as the previous ISF was imposed on the forged cake after it was rotated $90^{\circ}$ and preheated at $1150^{\circ} \mathrm{C}$ for $6 \mathrm{~h}$. Annealing was finally performed on the forged cake at $1000^{\circ} \mathrm{C}$ for $2 \mathrm{~h}$, followed by $\mathrm{FC}$ to $800^{\circ} \mathrm{C}$ and $\mathrm{AC}$ to room temperature. Specimens of the isothermally forged plate from the white zone in Figure 1 were cut to a dimension of approximately $10 \times 8 \times 2 \mathrm{~mm}$. The samples coated with high temperature paint (K-01 glass slurry) were heated at several selected temperature, followed by AC. Electro-polishing of specimens for light microscope (LM) and scanning electron microscope (SEM) observations was performed in a solution of $6 \%$ perchloric acid, $34 \%$ n-butyl alcohol, and $60 \%$ methanol electrolyte at $45 \mathrm{~V}$ and $-30^{\circ} \mathrm{C}$. The surface for LM observations was etched in a hydro-solution containing 3 vol.\% $\mathrm{HF}$ and 5 vol.\% $\mathrm{HNO}_{3}$. X-ray diffraction (XRD, Rigaku D/Max-2550) with $\mathrm{Cu} K_{\alpha}$ radiation $(\lambda=1.5418 \AA)$ was used to identify the phases at $50 \mathrm{kV}$ and $200 \mathrm{~mA}$ with diffraction angles $(2 \theta)$ from $10^{\circ}$ to $100^{\circ}$ with a step size of $0.02^{\circ}$ and $1 \mathrm{~s}$ in each step. SEM (Nano SEM 450, FEI Company, Hillsboro, OR, USA), transmission electron microscopy (TEM; Tecnai G2 S-Twin F20, FEI Company, Hillsboro, OR, USA), high-resolution transmission electron microscopy (HRTEM), high-angle annular dark-field scanning transmission electron microscopy (HAADF-STEM; E.A. Fischione Instruments, Westmoreland, PA, USA) and energy-dispersive X-ray spectroscopy (EDS) were conducted on the samples to identify the mechanisms of phase transformation. Thin foils for TEM were prepared through mechanical polishing to a thickness of 100-120 $\mu \mathrm{m}$ and then twin-jet electro-polishing with a solution of $6 \%$ perchloric acid, 34\% n-butyl alcohol, and $60 \%$ methanol electrolyte at $45 \mathrm{~V}$ and $-30{ }^{\circ} \mathrm{C}$. The hardness of samples was tested using a Vickers hardness tester (HVS-1000A; Huayin, Laizhou, Shandong, China) with a load of $4.9 \mathrm{~N}$ for $12 \mathrm{~s}$.

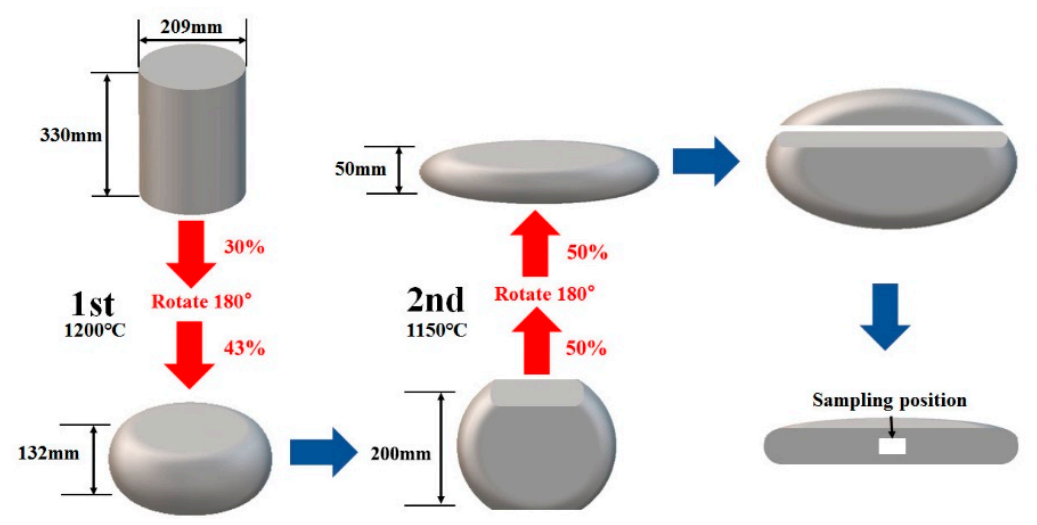

Figure 1. Schematic diagram of the two-step multi-directional isothermal forging and sampling position in the forged plate.

\section{Results and Discussion}

\subsection{Microstructure Analysis of Forged Samples before and after Heat Treatment (HT)}

As seen from Figure 2a, the microstructure of the isothermally forged alloy consists of fine grains and $\gamma / \alpha_{2}$ lamellar colonies. The $\gamma / \alpha_{2}$ lamellar colonies were twisted or broken due to isothermal forging, and the remaining broken lamellae seemed to extend perpendicular to the last-step forging direction. Similar results were reported in [11]. After heating at $900{ }^{\circ} \mathrm{C}$ for $6 \mathrm{~h}$, it can be seen from Figure $2 \mathrm{~b}$ that the microstructure of the forged alloy has hardly changed, suggesting good thermal 
stability. Moreover, a new kind of acicular lamellae, which were a little blurry, appeared in some grains circled in yellow. Figure 2c shows the microstructure of sample after heating at $1000{ }^{\circ} \mathrm{C} \mathrm{for} 1 \mathrm{~h}$, where two obvious changes occurred: (i) A lot of smaller grains with a diameter of $<5 \mu \mathrm{m}$ appeared in the areas of initial equiaxed grains, and (ii) More acicular lamellae, circled in Figure 2c, were extensively presented in the alloy. The newly-precipitated lamellae (NPL) were thinner than the initial lamellae and were not twisted. However, they were not observed in the sample after heating at $1160{ }^{\circ} \mathrm{C}$ for $1 \mathrm{~h}$ (Figure 2d), where the structure has vanished obviously.
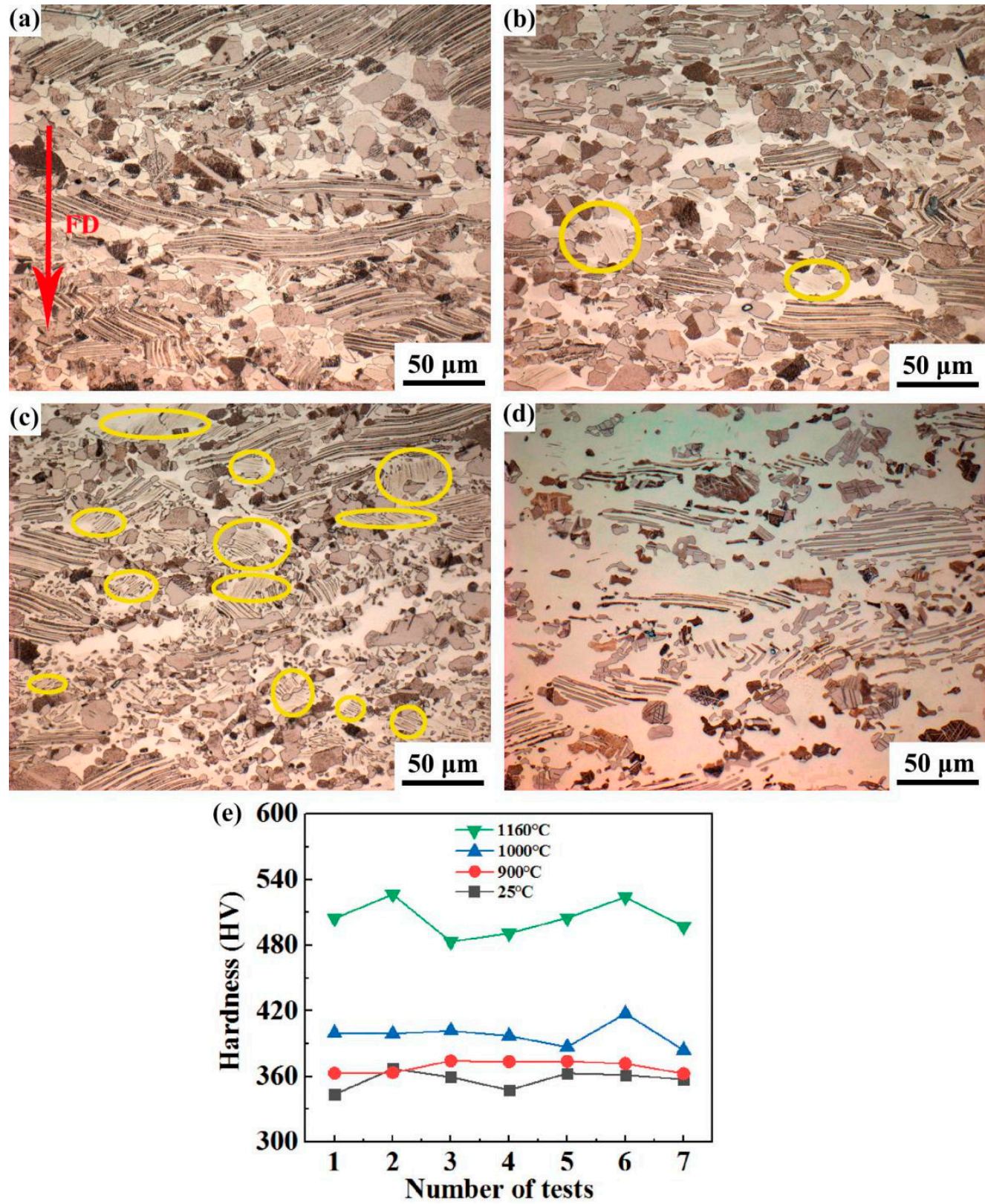

Figure 2. Microstructure of isothermally forged TiAl samples in different states: (a) forged sample; (b) heating at $900{ }^{\circ} \mathrm{C}$ for $6 \mathrm{~h}$; (c) heating at $1000{ }^{\circ} \mathrm{C}$ for $1 \mathrm{~h}$; (d) heating at $1160{ }^{\circ} \mathrm{C}$ for $1 \mathrm{~h}$. The last-step isothermal forging direction (FD) is marked (a); (e) the hardness of the forged samples in various conditions corresponding to samples $(\mathbf{a}-\mathbf{d})$.

Figure 2e shows the hardness values of the four samples, each of which has been tested seven times. On the whole, the hardness of the forged sample tended to increase with increasing heating temperature. Specifically, the hardness of the sample heated at $900^{\circ} \mathrm{C}$ for $6 \mathrm{~h}$ was very close to that of 
the sample without experiencing heating, which was consistent with the microstructural observation above. As the microstructure changed from 1000 to $1160^{\circ} \mathrm{C}$, the hardness increased more obviously. It has been reported that the relationship among the hardness values of the three phases in the alloy was $\beta_{\mathrm{o}}>\alpha_{2}>\gamma$ [12]. This suggests that the content of $\gamma$ phase in the forged sample was more likely to be reduced if phase transformation occurred during the heat treatment and caused the hardness to increase.

\subsection{Phase Transformation Studied with XRD}

Since obvious microstructural change occurred in the sample heated at $1000^{\circ} \mathrm{C}$, which was close to the upper limit of the service temperature of TiAl alloy, the forged sample heated at $1000{ }^{\circ} \mathrm{C}$ for $1 \mathrm{~h}$ (HT-1) was selected to compare with the initial forged sample. Significant changes are observed via XRD after HT-1. As shown in Figure 3, after heating the intensity increased for $\gamma(001), \gamma(110), \gamma(203)$ and $\gamma(004)$, while decreased for $\gamma(111), \gamma(201), \gamma(112)$ and $\gamma(222)$ and changed little for others. Almost all the intensities of $\alpha_{2}$ phase increased except for $\alpha_{2}(11 \overline{2} 0)$, which was separated from $\gamma(110)$ with almost no change. As for the intensity of B2 phases, both B2(110) and B2(200) peaks increased after HT-1. Generally, XRD diffraction intensity will increase as the phase content increases. Therefore, the content of $\alpha_{2}$ phase and B2 phase increased after HT-1. Since only three kinds of phases can be identified in the alloy, it can be inferred that the total amount of $\gamma$ phase decreased even if the intensity of some peaks increased, which is consistent with the three highest peaks of $\alpha_{2}, \gamma$ and B2 lying in-between 35-45 , suggesting that the refinement of grains in Figure $2 \mathrm{c}$ is actually a result of the dissolution of $\gamma$ grains through $\gamma \rightarrow \alpha_{2}+$ B2.
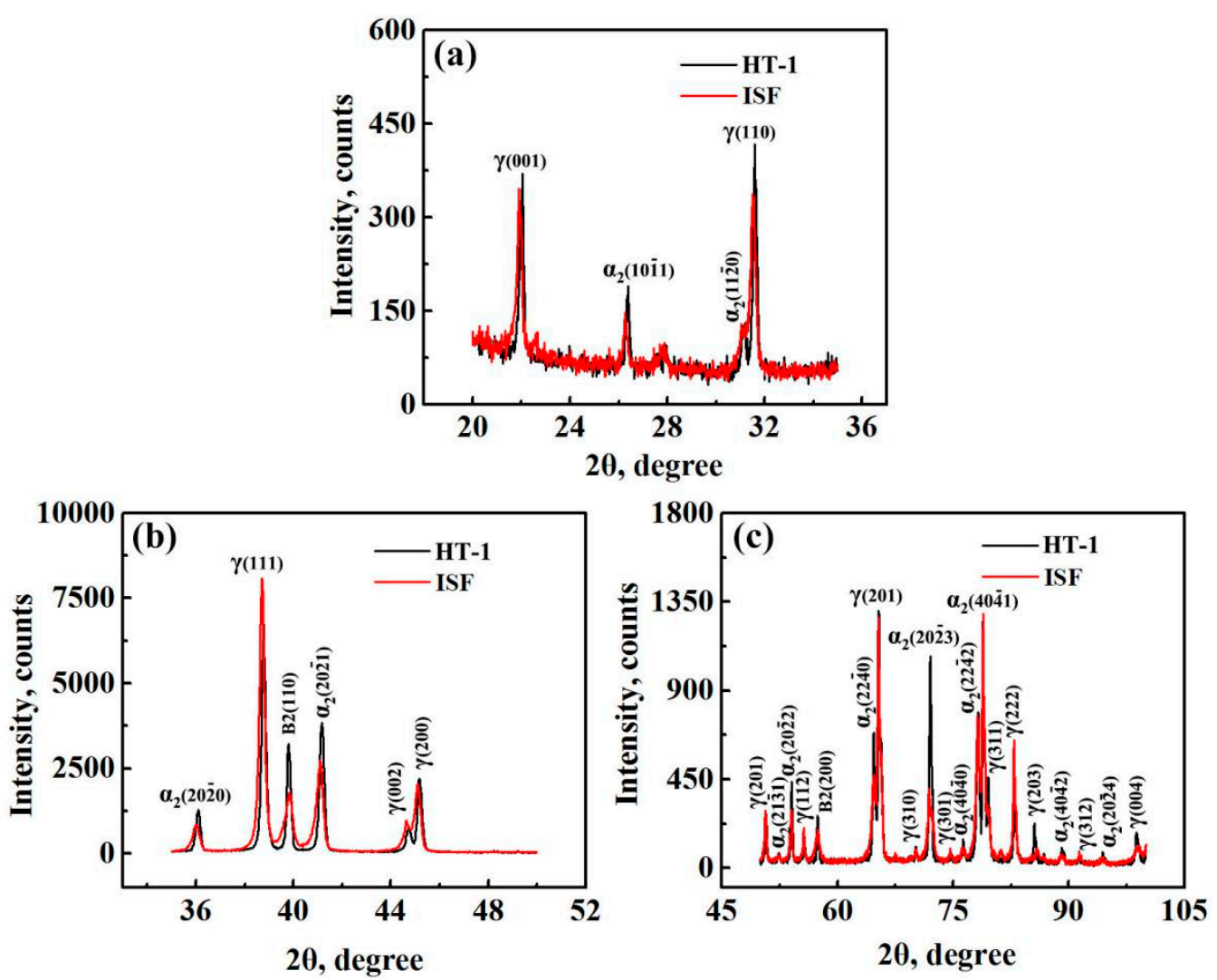

Figure 3. Comparison of $\mathrm{X}$-ray diffraction $(\mathrm{XRD})$ patterns between the samples in the states of isothermal forging (ISF) and isothermal forging $+1000^{\circ} \mathrm{C} / 1 \mathrm{~h} / \mathrm{AC}(\mathrm{HT}-1)$ (a) $20^{\circ}<2 \theta<35^{\circ}$; (b) $35^{\circ}<2 \theta<50^{\circ}$; (c) $50^{\circ}<2 \theta<100^{\circ}$. 
The rate of phase transformation will be very slow when the temperature is below $\mathrm{T}_{\min }$ [13]. Since the forged cake was heated at $1150^{\circ} \mathrm{C}$ for $6 \mathrm{~h}$ before the final-step forging (which lasted almost $160 \mathrm{~s}$ ), and then was directly air-cooled after forging at $1070{ }^{\circ} \mathrm{C}$, there was no sufficient time for the atomic diffusion to reach equilibrium considering its large size. In theory, only if the effect of temperature on the phase transition is considered, $\gamma$ lamellae should have been precipitated from the $\alpha_{2}$ phase [14] and increased during heating at $1000{ }^{\circ} \mathrm{C}$ through $\alpha_{2}^{S S} \rightarrow \alpha_{2}+\gamma$ according to the phase diagram [4]. This was actually confirmed since it happened in the small pieces in the heating process in the later part of this study. Then, the occurrence of $\gamma \rightarrow \alpha_{2}+B 2$ phase transition during heat treatment at $1000{ }^{\circ} \mathrm{C}$ is an abnormal phenomenon. During forging at high temperature, stress-induced phase transformation, mainly including $\gamma \rightarrow \alpha_{2}, \alpha_{2} \rightarrow \gamma$ and $\alpha_{2} \rightarrow$ B2, will occur in the TiAl-based alloy $[8,15,16]$. In the $(\alpha+\gamma+\beta / B 2)$ phase field, different strain amounts lead to different fractions of phases, and the fraction of $\gamma$ phase increases with increasing strain at the same temperature [11,17]. In other words, the atomic diffusion caused by stress-induced phase transformation in a short time is faster than that caused by temperature, and $\alpha_{2} \rightarrow \gamma$ transformation may be easier and faster than $\gamma \rightarrow \alpha_{2}$. However, there is no direct evidence to prove this up to now.

\subsection{Analysis of Newly Precipitated $\gamma$ Lamellae}

To study the precipitation mechanism of lamellae at $1000{ }^{\circ} \mathrm{C}$, a forged sample heated at $1000{ }^{\circ} \mathrm{C}$ for $24 \mathrm{~h}$ (HT-24) was used to compare with the sample HT-1. As circled in Figure 4a,b, the NPL became denser and clearer after heating at $1000^{\circ} \mathrm{C}$ for $24 \mathrm{~h}$. Figure $4 \mathrm{c}, \mathrm{d}$ and e show the BSE (backscattered electron) images of $\alpha_{2}$ grains in the initial forged sample and the samples of HT-1 and HT-24, where the dark phase is $\gamma$ phase, the gray one is $\alpha_{2}$ phase, and the white one is B2 phase. The NPL were not obvious in the initial forged TiAl (Figure 4c) and coarsened at heating process (Figure 4d,e). In a word, it is beneficial to keep the forged sample heated at $100{ }^{\circ} \mathrm{C}$ for the precipitation of lamellae.
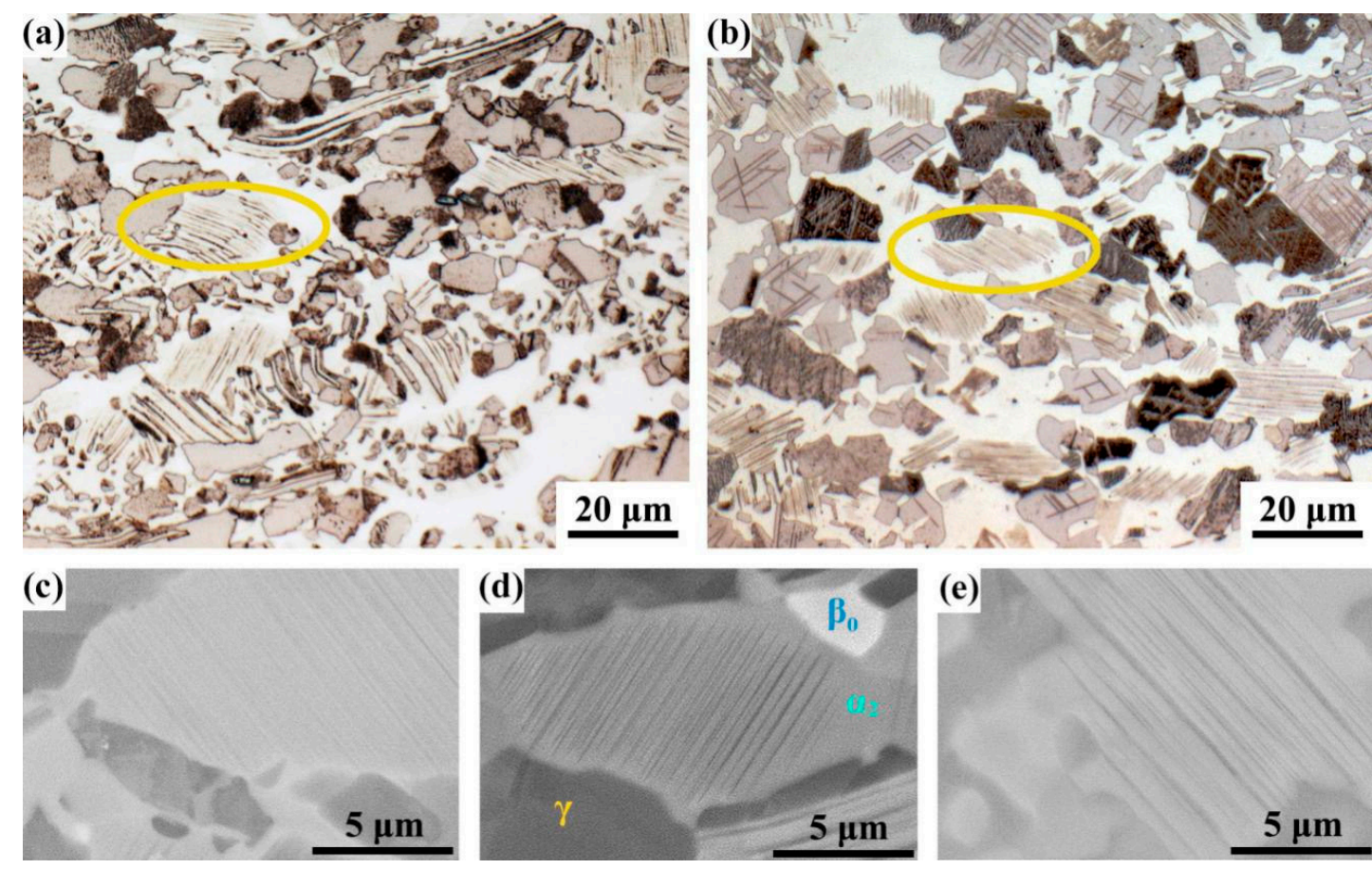

Figure 4. Light microscope (LM) images $(\mathbf{a}, \mathbf{b})$ and BSE images (c-e) of newly precipitated lamellae in the forged samples of HT-1 (a,d), HT-24 (b,e) and sample with no heating process (c).

Figure 5a-c shows the high-angle annular dark-field (HAADF) image of NPL in $\alpha_{2}$ grains observed in the initial forged sample. The precipitated lamellae are parallel to each other and are less than $100 \mathrm{~nm}$ in thickness, which cannot be observed under LM. The nano-thickness NPL in $\alpha_{2}$ grains may 
be formed by the previous annealing after forging. Most of the NPL almost reach the grain boundary (Figure 5a), but it can be seen that the NPL near the grain boundary are finer and somewhat needle-like. Some NPL cannot reach the grain boundary of $\alpha_{2}$ grains, and the density in the interior of $\alpha_{2}$ grain is larger than that near the grain boundary (Figure $5 b$ ). The coarsest part of NPL is inside the grain and both ends of some NPL did not reach the grain boundary, as indicated by the arrows in Figure 5c. It follows that NPL first appeared inside the $\alpha_{2}$ grains rather than the grain boundary, which is different from the mechanism reported in [18]. After heating at $1000^{\circ} \mathrm{C}$ for $1 \mathrm{~h}$, the grains of $\alpha_{2}$ phase grew up by devouring the $\gamma$ grains, resulting in both ends of NPL being farther away from the grain boundary, which can be seen in Figure 5d. Interestingly, the NPL inside the grain were not swallowed by the $\alpha_{2}$ phase but thicker than those before the heat treatment (Figure 5e). This means that NPL were continuously precipitated inside the $\alpha_{2}$ grains while $\alpha_{2}$ grains devoured $\gamma$ grains, that is, $\alpha_{2} \rightarrow \gamma$ and $\gamma \rightarrow \alpha_{2}$ phase transformations occurred simultaneously or dynamically in the process of heat treatment. Figure $5 \mathrm{f}$ shows a selected area electron diffraction (SAED) pattern of position 1 in Figure 5e under TEM, revealing that the NPL and the parent phase maintain the Blackburn relationship: (111) $\gamma / /(0001) \alpha_{2}$.
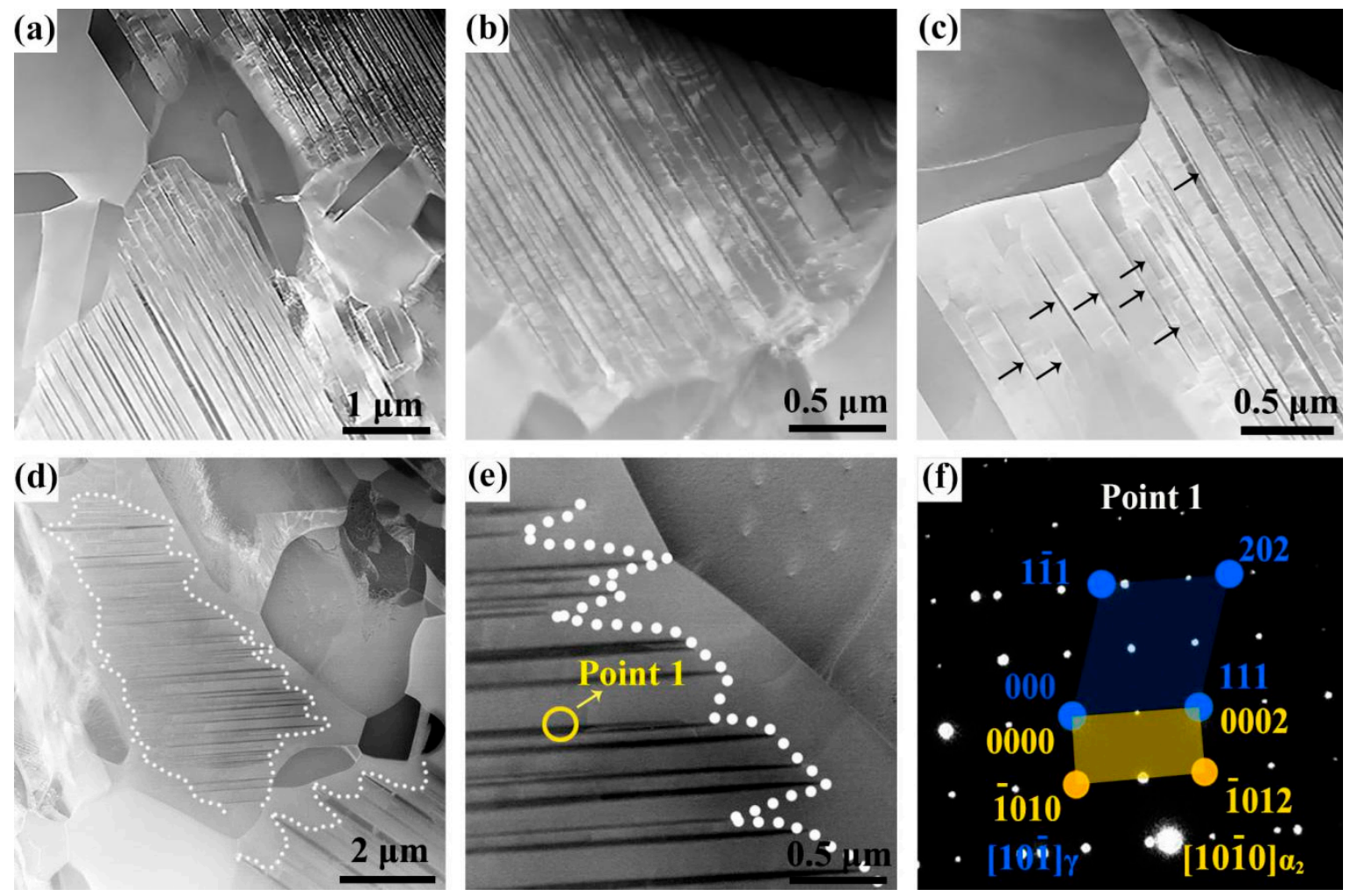

Figure 5. The high-angle annular dark-field (HAADF) images of initial isothermally forged TiAl (a-c) and HT-1 (d,e), where (f) is the selected area diffraction pattern from location 1 in $(\mathbf{e})$.

\subsection{Atomic Diffusion in HT-1 Sample}

EDX analysis under HADDF was performed in the samples before and after heat treatment, with at least three points in each phase determined. As seen from Table 1, after heat treatment the concentration of $\mathrm{Al}$ increased in $\alpha_{2}$ phase, and decreased in equiaxed $\gamma$ phase. The concentration difference may provide a driving force for $\gamma \rightarrow \alpha_{2}$ in the heating process at $1000^{\circ} \mathrm{C}$. However, the atomic percent of NPL inside $\alpha_{2}$ grains increased slightly, which is different from the equiaxed $\gamma$ grains. This means that the NPL have nothing to do with the initial equiaxed $\gamma$ grains and are not precipitated from grain boundaries. Thus, the increase of $\mathrm{Al}$ concentration in $\alpha_{2}$ phase should be the only reason to promote the precipitation and coarsening of $\gamma$ lamellae (Figure 5e), except that the stacking fault itself can easily 
cause the segregation of solute elements. The higher Al concentration in the equiaxed $\gamma$ grains of the initial forged sample may be attributed to a stress-induced phase transition, which needs further study.

Table 1. Atomic percent (at.\%) of Ti and $\mathrm{Al}$ elements in $\alpha_{2}$ phase and $\gamma$ phase in the isothermally forged TiAl alloy and the isothermally forged sample after heat treatment at $1000{ }^{\circ} \mathrm{C}$ for $1 \mathrm{~h}$.

\begin{tabular}{|c|c|c|c|c|c|c|}
\hline \multirow{3}{*}{ State } & \multirow{2}{*}{\multicolumn{2}{|c|}{$\alpha_{2}$ Phase }} & \multicolumn{4}{|c|}{$\gamma$ Phase } \\
\hline & & & \multicolumn{2}{|c|}{ Equiaxed Grains } & \multicolumn{2}{|c|}{ Precipitated Lamellae } \\
\hline & $\mathrm{Ti}$ & Al & Ti & Al & $\mathbf{T i}$ & Al \\
\hline ISF & 64.3 & 35.7 & 47.7 & 52.3 & 49.1 & 50.9 \\
\hline $\mathrm{ISF}+1000^{\circ} \mathrm{C} / 1 \mathrm{~h} / \mathrm{AC}$ & 60.2 & 39.8 & 48.9 & 51.1 & 48.2 & 51.8 \\
\hline
\end{tabular}

\subsection{Mechanisms of Dynamic Phase Transformation}

Figure 6a shows the TEM image of NPL in the sample after heat treatment. To figure out the precipitation mechanism of $\gamma$ lamellae, the portion of a relatively thin and short precipitated lamella circled in Figure 6a was observed via HRTEM. As shown in Figure 6b, this lamella is not $\gamma$ phase but a stacking fault of $\alpha_{2}$ phase. Figure 6c shows the Fast Fourier Transformation (FFT) image of $\alpha_{2}$ phase (point 1 in Figure 6b). It has been reported that the nucleation of $\gamma$-lamellae proceeds from grain boundaries or stacking faults on the (0001) $\alpha_{2}$ basal plane [14]. There are lots of different points of view on the formation mechanism of stacking faults in $\alpha_{2}$ phase [19-22], where the main view is that stacking faults originate from grain boundaries or are caused by the cross-slip of Shockley dislocations from grain boundaries to basal planes [23]. Due to the order-disorder phase transition of $\alpha_{2} \rightarrow \alpha$, the $c / a$ ratio of $\alpha_{2}$-phase decreases when the temperature approaches or exceeds $\mathrm{T}_{\min }$ (being $1160{ }^{\circ} \mathrm{C}$ ) [24], which may be another reason for the formation of stacking faults in $\alpha_{2}$ phase. Once the internal stacking faults of $\alpha_{2}$ phase are formed, the element segregation would occur near them at a high temperature. This is also the reason why lamellae can be precipitated when the concentration of $\mathrm{Al}$ in $\alpha_{2}$ phase is low (Table 1). The newly grown areas of $\alpha_{2}$ grains in the heating process at $1000{ }^{\circ} \mathrm{C}$ (Figure $5 \mathrm{~d}, \mathrm{e}$ ) do not experience the process of forging or order-disorder phase transition, thus there are no conditions for stacking faults to form in these freshly grown areas. Besides, the newly formed $\alpha_{2}$ phase is close to the equilibrium state at $100{ }^{\circ} \mathrm{C}$, so the element supersaturation is absent there. It follows that NPL do not continue to extend after heat treatment, but only coarsen after reaching the original grain boundary, as shown by the dotted curves in Figure 5d,e.
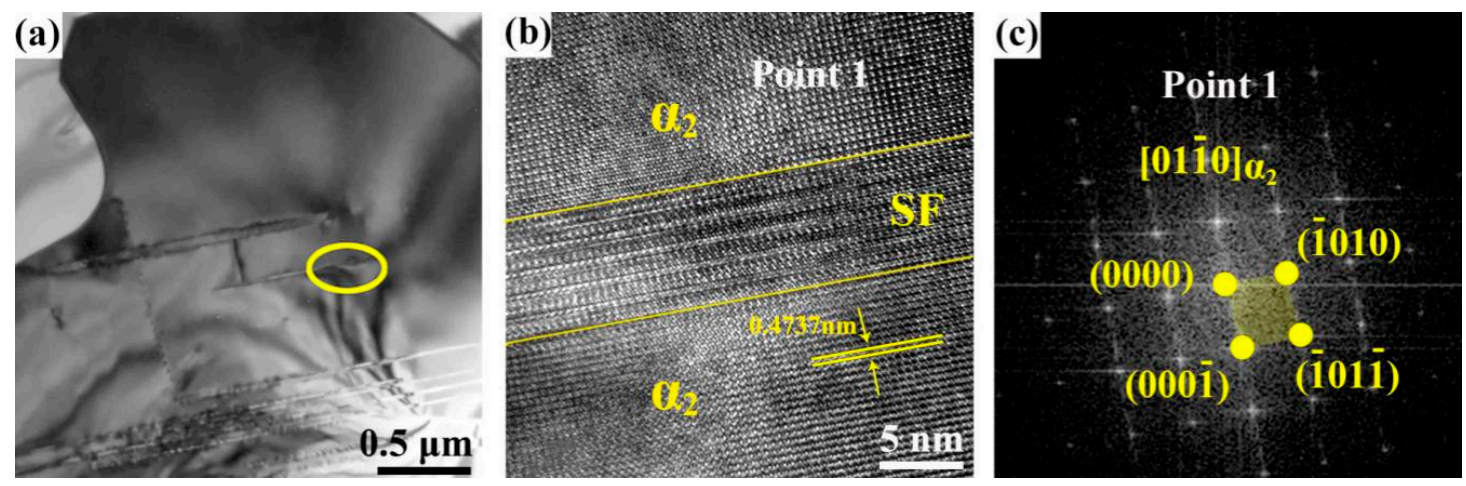

Figure 6. (a) Transmission electron microscopy (TEM) image of precipitated lamellae in the interior of $\alpha_{2}$ grain, (b) high-resolution transmission electron microscopy (HRTEM) image of stacking faults, (c) Fast Fourier Transformation (FFT) pattern of point 1 in (b).

Figure 7 shows the whole process of phase transformations of $\alpha_{2} \leftrightarrow \gamma$ observed in this study. First, a large number of stacking faults occur inside $\alpha_{2}$ grains in the process of forging or order-disorder phase transition of $\alpha \rightarrow \alpha_{2}$. Second, Al atoms in the $\alpha_{2}$ grains are preferred to migrate into the 
stacking faults, forming the nano-thickness lamellae under the action of temperature after forging. Third, when heated to $1000^{\circ} \mathrm{C}, \mathrm{Al}$ atoms in $\gamma$ grains migrate into $\alpha_{2}$ grains, causing $\gamma$ grains to be dissolved and gradually transformed into $\alpha_{2}$ phase, and the $\mathrm{Al}$ atoms entering the $\alpha_{2}$ phase will further gather at the stacking faults of $\alpha_{2}$ phase and newly formed $\gamma$ lamellae, which promotes the precipitation and coarsening of the $\gamma$ lamellae in the $\alpha_{2}$ grains.

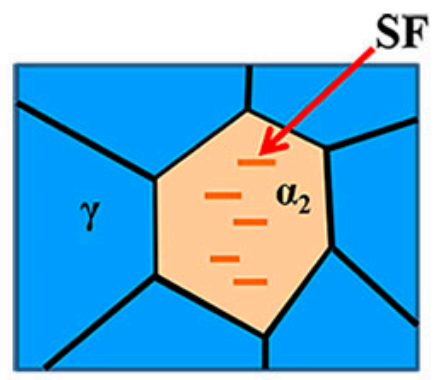

Step 1

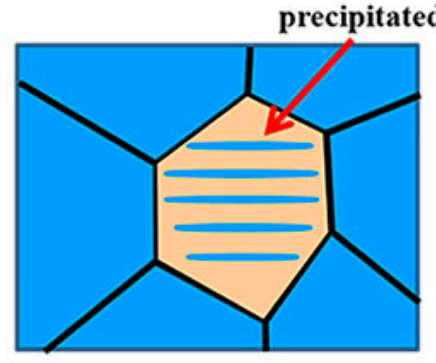

Step 2

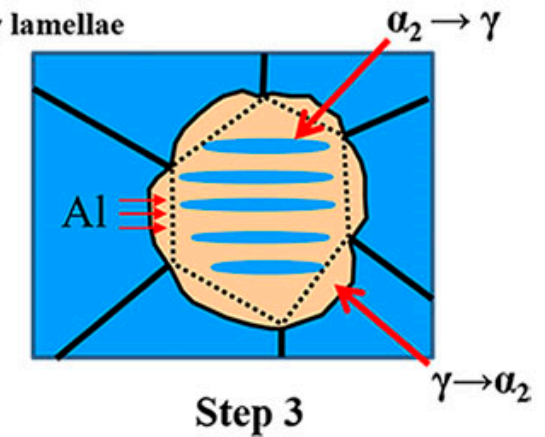

Step 3

Figure 7. Schematic illustration of phase transitions $\alpha_{2} \leftrightarrow \gamma$ proposed in this study.

\section{Conclusions}

The microstructure of the forged beta-gamma intermetallic alloy changed obviously because of phase transformation when heating in the range of $1000-1160^{\circ} \mathrm{C}$, leading to the increase in the hardness with increasing heating temperature. The stress-induced phase transformation in the forging process decreased the concentration of $\mathrm{Al}$ in $\alpha_{2}$ grains and increased the volume fraction of $\gamma$ phase in a short time, providing a driving force for the dissolution of $\gamma$-phase in the forged TiAl-based alloy through $\gamma$ $\rightarrow \alpha_{2}+\mathrm{B} 2$ phase transformation when heated at $1000^{\circ} \mathrm{C}$, which was a result of decomposition of $\mathrm{Al}$ in $\gamma$ grains. The precipitation of $\gamma$ lamellae in the $\alpha_{2}$ grains through $\alpha_{2} \rightarrow \gamma$ was due to the preferential enrichment of $\mathrm{Al}$ at stacking faults. In a word, the dynamic phase transformations of $\alpha_{2} \rightarrow \gamma$ and $\gamma \rightarrow \alpha_{2}$ occur simultaneously.

Author Contributions: S.Q., A.F, and J.S. designed and supervised the project, and produced the samples; Z.Z. conducted the experiments under the guidance of S.Q., A.F., J.S, and D.C.; All the authors analyzed the data and discussed the results; Z.Z. wrote the initial manuscript; S.Q., A.F., G.C., and D.C. revised and edited the article.

Funding: This research was funded by the National Natural Science Foundation of China (NSFC), Grant Number: 51871168, and the Natural Sciences and Engineering Research Council of Canada (NSERC) in the form of international research collaboration.

Conflicts of Interest: The authors declare no conflict of interest.

\section{References}

1. Appel, F.; Paul, J.; Oehring, M. Gamma Titanium Aluminides: Science and Technology; Wiley-VCH Verla GmbH \&Co. KGaA: Weinheim, Germany, 2011; pp. 1-30.

2. Wu, G.D.; Cui, G.R.; Qu, S.J.; Feng, A.H.; Cao, G.J.; Ge, B.H.; Xiang, H.P.; Shen, J.; Chen, D.L. High-temperature oxidation mechanisms of nano-/submicro-scale lamellar structures in an intermetallic alloy. Scripta Mater. 2019, 171, 102-107. [CrossRef]

3. Qu, S.J.; Tang, S.Q.; Feng, A.H.; Feng, C.; Shen, J.; Chen, D.L. Microstructural evolution and high-temperature oxidation mechanisms of a titanium aluminide based alloy. Acta Mater. 2018, 148, 300-310. [CrossRef]

4. Qiu, C.; Liu, Y.; Zhang, W.; Liu, B.; Liang, X. Development of a Nb-free TiAl-based intermetallics with a low-temperature superplasticity. Intermetallics 2012, 27, 46-51. [CrossRef]

5. Huang, Z.W. Thermal stability of Ti-44Al-4Nb-4Hf-0.2Si-1B alloy. Intermetallics 2013, 37, 11-21. [CrossRef]

6. Schwaighofer, E.; Clemens, H.; Mayer, S.; Lindemann, J.; Klose, J.; Smarsly, W.; Güther, V. Microstructural design and mechanical properties of a cast and heattreated intermetallic multi-phase $\gamma$-TiAl-based alloy. Intermetallics 2014, 44, 128-140. [CrossRef] 
7. Huang, Z.W.; Lin, J.P.; Sun, H.L. Microstructural changes and mechanical behaviour of a near lamellar $\gamma$-TiAl alloy during long-term exposure at $700{ }^{\circ} \mathrm{C}$. Intermetallics 2017, 85, 59-68. [CrossRef]

8. Derder, C.; Bonnet, R.; Pe'nisson, J.M.; Frommeyer, G. Evidence of stress-induced $\alpha_{2} \rightarrow \gamma$ transformation in a Ti-30 at.\%Al alloy. Scripta Mater. 1997, 38, 757-762. [CrossRef]

9. Zhang, W.J.; Lorenz, U.; Appel, F. Recovery, recrystallization and phase transformations during thermomechanical processing and treatment of TiAl-based alloys. Acta Mater. 2000, 48, 2803-2813. [CrossRef]

10. Zhu, K.; Qu, S.J.; Feng, A.H.; Sun, J.L.; Shen, J. Microstructural evolution and refinement mechanism of a beta-gamma TiAl-based alloy during multidirectional isothermal forging. Materials 2019, 12, 2496. [CrossRef]

11. Zhu, K.; Qu, S.J.; Feng, A.H.; Sun, J.L.; Shen, J. Evolution of the microstructure and lamellar orientation of a $\beta$-Solidifying $\gamma$-TiAl-based alloy during hot compression. Metals 2018, 8, 445. [CrossRef]

12. Schloffer, M.; Iqbal, F.; Gabrisch, H.; Schwaighofer, E.; Schimansky, F.P.; Mayer, S.; Stark, A.; Lippmann, T.; Göken, M.; Pyczak, F.; et al. Microstructure development and hardness of a powder metallurgical multi phase $\gamma$-TiAl-based alloy. Intermetallics 2012, 22, 231-240. [CrossRef]

13. Erdely, P.; Werner, R.; Schwaighofer, E.; Clemens, H.; Mayer, S. In-situ study of the time-temperature-transformation behaviour of a multi-phase intermetallic $\beta$-stabilised TiAl alloy. Intermetallics 2015, 57, 17-24. [CrossRef]

14. Wei, D.X.; Koizumi, Y.; Nagasako, M.; Chiba, A. Refinement of lamellar structures in Ti-Al alloy. Acta Mater. 2017, 125, 81-97. [CrossRef]

15. Du, X.W.; Zhu, J.; Zhang, X.; Cheng, Z.Y.; Kim, Y.W. Creep induced $\alpha_{2} \rightarrow$ B2 phase transformation in a fully-lamellar TiAl alloy. Scripta Mater. 2000, 43, 597-602. [CrossRef]

16. Wang, J.G.; Chen, G.L.; Zhang, L.C.; Ye, H.Q. Study on the stress-induced $\gamma+\alpha_{2}$ transformation in a hot-deformed Ti-45Al-10Nb alloy by high-resolution transmission electron microscopy. Mater. Lett. 1997, 31, 179-183. [CrossRef]

17. Liu, S.Q.; Shen, J. Microstructural evolution and high-temperature oxidation mechanisms of a titanium aluminide based alloy. Mater. Res. Express 2018, 5, 096516. [CrossRef]

18. Qin, G.W.; Hao, S.; Sun, X.D. Ledge mechanism of primary $\alpha_{2} / \gamma$ lamellae growing in the supersaturated $\alpha_{2}$ matrix for $\gamma$-TiAl-based $\left(\gamma+\alpha_{2}\right)$ alloy. Scripta Mater. 1998, 39, 289-293. [CrossRef]

19. Zghal, S.; Thomas, M.; Naka, S.; Finel, A.; Couret, A. Phase transformations in TiAl-based alloys. Acta Mater. 2005, 53, 2653-2664. [CrossRef]

20. Denquin, A.; Naka, S. Phase transformation mechanisms involved in two-phase TiAl-based alloys-II. discontinuous coarsening and massive-type transformation. Acta Mater. 1996, 44, 353-365. [CrossRef]

21. Denquin, A.; Naka, S. Phase transformation mechanisms involved in two-phase TiAl-based alloys-I, lamellar structure formation. Acta Mater. 1996, 44, 343-352. [CrossRef]

22. Karadge, M.; Gouma, P.; Philos, I. A structural aspect of $\alpha\left(\alpha_{2}\right) \rightarrow$ lamellar $\alpha_{2}+\gamma$ transformation in $\gamma$-TiAl. Mag. Lett. 2006, 84, 451-459.

23. Koizumi, Y.; Fujita, T.; Minamino, Y.; Hata, S. Effects of plastic deformation on lamellar structure formation in Ti-39 at.\% Al single crystals. Acta Mater. 2010, 58, 1104-1115. [CrossRef]

24. Yeoh, L.A.; Liss, K.D.; Bartels, A.; Chladil, H.; Avdeev, M.; Clemens, H.; Gerling, R.; Buslaps, T. In situ high-energy $\mathrm{X}$-ray diffraction study and quantitative phase analysis in the $\alpha+\gamma$ phase field of titanium aluminides. Scripta Mater. 2007, 57, 1145-1148. [CrossRef]

(C) 2019 by the authors. Licensee MDPI, Basel, Switzerland. This article is an open access article distributed under the terms and conditions of the Creative Commons Attribution (CC BY) license (http://creativecommons.org/licenses/by/4.0/). 